\title{
A Longitudinal Analysis of the Relationship Between the Trajectory of Mobile Phone Dependency, Social Capital, and Depression in Early Adolescents
}

\author{
Jieun $\mathrm{Kim}^{1}$, Saerom Park ${ }^{2}$, Hye Jun Park ${ }^{3}$ \\ Ph. D. Candidate, Department of Child \& Family Studies, Seoul National University, Seoul, Korea ${ }^{1}$ \\ Ph. D., Department of Child \& Family Studies, Seoul National University, Seoul, Korea ${ }^{2}$ \\ Professor, Department of Child \& Family Studies, Seoul National University, Seoul, Korea ${ }^{3}$

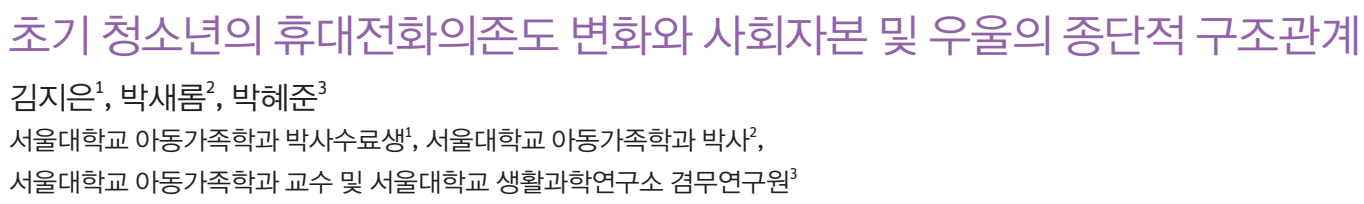

Objectives: The study aimed to investigate the trajectory of mobile phone dependency and determine the longitudinal pathways between the trajectory of mobile phone dependency, social capital, and depression in early adolescents.

Methods: This study used data from the 2nd to 5th wave of the 2,378 4th graders panel of the Korea Children and Youth Panel Survey 2010 (KCYPS 2010). Data were analyzed using Pearson's correlations, Latent Growth Modeling (LGM), and Structural Equation Modeling (SEM) using SPSS 20.0 and AMOS 20.0.

Results: First, from the fifth to eighth grade, the trajectory of mobile phone dependency of early adolescents increased over time, but the trend has gradually decreased. Second, in the fifth grade, the more psychological and emotional support one experienced from parents, peers, and teachers, the lower the intercept of mobile phone dependency, and the slower the trend of change in growth over time. Third, the mobile phone dependency in the fifth grade had a significant effect on depression in the eighth grade. Lastly, while social capital in early adolescence did not show a significant direct effect on depression, it had an indirect effect on depression through the intercept of mobile phone dependency.

Conclusion: The results of this study suggest that supportive social relationships can be an important protective factor against mobile phone dependency and the emotional health of early adolescents. For prospective intervention in mobile phone dependency, it would be necessary to help early adolescents develop supportive relationships with parents, peers, and teachers and have positive emotional experiences with them.

Keywords: mobile phone dependency, social capital, depression, early adolescents, longitudinal analysis, longitudinal analysis, Korea Children and Youth Panel Survey

\section{Introduction}

미디어 사용의 증가는 10 대 초에 정점을 이룬다(Rideout,

Corresponding Author: Saerom Park, Ph. D., Department of Child \& Family Studies, Seoul National University, 1 Gwanak-ro, Gwanak-gu, Seoul, Korea

E-mail: dplum11@snu.ac.kr
Foehr, \& Roberts, 2010). 특히 우리나라의 스마트폰 보급률은 세계에서 가장 높다고 알려져 있으며(Cha \& Seo, 2018), 지난 10 여 년간 청소년의 스마트폰 보유율 또한 급속하게 증가하

(C)The Korean Association of Child Studies

This is an Open Access article distributed under the terms of the Creative Commons Attribution Non-Commercial License (http:// creativecommons.org/licenses/by-nc/4.0) which permits unrestricted noncommercial use, distribution, and reproduction in any medium, provided the original work is properly cited. 
였다. 이 결과 중학생은 $97.8 \%$ 가 휴대전화를 가지고 있고, 초 등학교 고학년 10명 중 9명은 휴대전화를 소유하고 있는 것으 로 나타났다(Y. Kim, 2019). 정보통신정책연구원 보고(Y. Kim, 2019)에 따르면 휴대전화를 소유한 초등학교 고학년 중에서 $81.2 \%$ 는 스마트폰을 사용하고 있었으며, 스마트폰을 소유하 는 비율의 증가가 초기 청소년 시기에 가장 높게 나타났다. 초 등학교 고학년의 휴대전화 이용 시간은 하루 평균 1 시간 45 분 으로, 이는 3년 전과 비교하였을 때 $73 \%$ 증가한 수준이다(Y. $\mathrm{Kim}, 2019)$. 오늘날 우리나라의 10대 대부분은 스마트폰으로 대표되는 자신의 휴대전화를 보유하고 있고, 이는 초기 청소 년이 휴대전화를 더 빈번하게 이용할 수 있는 환경이 된다.

초기 청소년은 일반적으로 만 10세부터 14세에 해당하는 청 소년을 의미한다(UNICEF, 2011). 이 시기에 청소년은 신체, 인 지, 정서를 포괄하는 모든 측면에서 급격하게 성장하며, 중등교 육으로 넘어가는 과도기(transition)를 경험한다. 초기 청소년은 급격한 신체적 성장과 이차성징, 인지 발달의 불균형 등으로 인 하여 심리적으로 취약해지기 쉽고, 또래관계와 학업 부담 등으 로 불안정한 정서와 행동을 보일 수 있다. 우리나라 청소년은 $\mathrm{OECD}$ 국가 간 비교를 통해 보았을 때 학업 스트레스가 매우 높은(M. Kim, 2015) 반면, 놀이와 여가를 즐길 시간이 부족하다 (M.-H. Cho, 2004). 이러한 사회문화적 맥락에서 많은 청소년은 휴대전화를 이용하여 게임 및 오락, SNS와 메신저 등을 하며 스 트레스를 해소한다(Cha \& Seo, 2018; Yang \& Park, 2005).

초기 청소년은 휴대전화를 이용하여 즐거움을 찾을수록 휴 대전화를 과도하게 사용하고 이에 의존하기 쉽다(Jun, 2015; M. Seo, 2016). 또한 청소년이 휴대전화를 습관적으로 자주 사용할 때(Oulasvirta, Rattenbury, Ma, \& Raita, 2012) 휴대전 화에 의존할 가능성이 커진다고 알려져 있다(S. Kim, 2016; S. Kim \& Han, 2015; Y.-S. Kim, 2019). 휴대전화의존은 청소 년이 휴대전화를 과도하게 사용하고 통제력을 상실하여, 이 를 사용하지 못할 때 불안이나 초조함 등을 느끼는 상태를 의 미한다(Jun, 2015; S. H. Lee et al., 2002). 정보통신정책연구원 (Korea Information Society Development Institute [KISDI]) STAT Report (Y. Kim, 2019)는 초기 청소년의 휴대전화 이용이 초등 학교 저학년에 비교하였을 때 2.5 배가량 증가하였고, 이와 더 불어 휴대전화의존도가 높아진다고 보고했다.

휴대전화를 소유하고 사용하는 나이가 점차 낮아지면서 (Cha \& Seo, 2018) 휴대전화의존에 따른 발달 문제가 학령기 에서 심각하게 나타나고 있다(Jun, 2015). 휴대전화를 과도하 게 사용하는 청소년은 두통, 피로감과 같은 신체 증상뿐만 아 니라 즉각적인 만족 추구 및 충동적 성향이 나타난다고 알려
져 있다(S. Kim, 2016). 또한, 일반 청소년과 비교하였을 때 우 울, 불안, 만성 스트레스 등 부정적인 심리.정서 문제를 더 많 이 경험한다고 보고되었다(Elhai, Dvorak, Levine, \& Hall, 2017; J. M. Kim \& Song, 2015; S. Kim, 2016).

청소년이 휴대전화에 지나치게 의존할 때 발생하는 개인의 정서 문제 중에서도 우울은 휴대전화의존과 밀접한 관계가 있 는 것으로 알려져 있다(Elhai et al., 2017; Jun, 2015; A.-R. Lee \& Lee, 2012). 우울은 청소년이 스스로 슬프고 불행하다고 느끼는 부정적 정서이며, 일상에서 보편적으로 경험할 수 있는 심리적 장애를 의미한다(Baek \& Chung, 2015). 우울은 휴대전화 과다 사용 및 의존과 연결되는 심리적 특성으로 주목받고 활발히 연 구되었다(Elhai et al., 2017). 대부분의 연구에서 우울은 휴대전 화의존과 정적 상관을 보인다고 보고되었으나, 두 변인 간 인 과적 방향성에 관해서는 여전히 명확한 결과가 밝혀지지 않았 다(Bae, 2014; Baek \& Chung, 2015; Jun, 2015; S. Kim, 2016).

청소년의 우울은 휴대전화의존을 설명하는 주요한 심리적 특성이다(Ehai et al., 2018; Jin \& Shin, 2016; Mo, 2018; Yang \& Park, 2005). 그러나 횡단적 수준에서 두 변인의 인과관계를 밝 히는 데는 분명한 한계가 있다(Bae, 2014; $\mathrm{Ha}, 2014)$. 최근 종단 연구는 초기 청소년이 휴대전화에 의존하는 과정에서 우울과 같은 심리.정서 문제를 경험한다는 결과를 보고하였다(Baek \& Chung, 2015; Jun, 2015; S. Kim, 2016). S. Kim (2016)은 중학 교 2학년부터 고등학교 1학년까지 종단 자료를 분석하여 청 소년이 전년도에 휴대전화를 많이 사용하고 의존할수록 다음 연도의 우울이 증가한다고 보고하였다. Beak과 Chung (2015) 의 연구에서도 시간의 흐름에 따라 중 2 에서 고 1 사이 휴대전 화의존도가 청소년의 우울에 지속적인 영향을 미친다고 나타 났다. Jun (2014)은 중·고등학생 시기에 걸쳐 전년도 휴대전화 의존이 다음 해 우울에 정적인 영향을 미쳤으나, 이전 시점의 우울이 이후 휴대전화의존에는 영향을 미치지 않는다고 밝혔 다. 또한, Lapierre, Zhao와 Custer (2019)의 단기 종단연구에서 도 스마트폰 의존은 3 개월 후 청소년의 우울 증상을 예측하였 다. 이처럼 최근 몇몇 종단연구에서 청소년의 휴대전화의존이 우울에 선행한다는 결과가 제시되고 있다. 그러나 여전히 종 단분석을 통해 초기 청소년의 휴대전화의존과 우울의 관계를 밝힌 연구는 매우 부족한 실정이다. 따라서 본 연구에서는 초 등학교 고학년 휴대전화의존이 이후 중학생 시기의 우울을 예 측할 수 있는지 살펴보고자 한다.

초기 청소년은 부모, 친구, 교사와 같은 가까운 관계와 결 속하고 지지받는 정도에 따라 주관적 안정감을 다르게 느낀 다(Coleman, 1990; Putnam, 1993). 청소년이 가까운 관계로부 
터 받는 사회적 유대, 상호 간의 호혜(reciprocity)와 지지는 광 의적 개념인 사회자본(social capital)으로 살펴볼 수 있다. 사회 자본에는 신뢰, 관계망, 규범 등의 요소가 포함된다(Bae, 2018; Coleman, 1990; J. A. Seo, 2013; Wu et al., 2010). 청소년의 사회 자본은 일상에서 영향을 받는 사회적 관계의 질을 의미하며 (Coleman, 1990), 이는 청소년기의 심리.정서 문제에 매우 강 력한 영향을 미친다고 알려져 있다(Bae, 2018; Heo, 2015; Mo, 2018; Parcel \& Dufur, 2001; Wu et al., 2010; Yang \& Park, 2005).

청소년에게 가장 기본적인 사회자본의 형태는 가족이다 (Putnam, 1995). 가족 내 사회자본은 기본적으로 부모와 자녀 사이의 유대를 의미하며 부모의 관심, 감독, 의사소통 방식 등 을 내포한다(Coleman, 1990; Parcel \& Dufur, 2001). 부모가 자 녀에게 적절한 관심을 보이며 소통하고 감독하는 데에 시간 과 주의를 기울일 때, 자녀의 문제 행동은 감소하고 안녕감 (well-being)은 높아지며 전반적 발달이 증진된다고 밝혀졌다 (Coleman, 1990; Otto \& Atkinson, 1997; Wu et al., 2010). 이와 반대로 부모가 자녀에게 적절한 심리적 지지를 제공하지 못하 고 방임하거나 부정적 양육 태도를 보일 때 청소년은 우울과 같은 심리.정서 문제를 경험할 수 있다. Wu 등 (2010)은 사회 자본이론을 적용하여 청소년의 우울을 이해하고자 하였는데, 이들은 가족의 사회자본이 청소년의 우울 증상에 중추 역할을 한다고 보고했다.

가정과 더불어 학교는 청소년이 많은 시간을 보내며 다양한 사회적 관계를 맺는 중요한 장소이다. 초기 청소년기에는 또래 관계를 비롯한 학교 내 관계가 더욱 중요해진다. 특히 또래와 친밀한 관계를 형성하고 안정감을 느낄 때 청소년은 사회적 유 능감을 느낀다(Laible, 2007). 긍정적인 또래관계는 청소년의 우 울을 낮추는 변인으로 일관되게 보고되며(Mo, 2018) 초기 청 소년에게 중요한 심리 사회적 자원을 제공한다(Dika \& Singh, 2002)고 알려져 있다. 선행연구에 따르면 청소년이 또래 및 교 사와 긍정적 관계를 형성할 때 학교생활의 전반적 만족도가 높 아지고, 결과적으로 청소년의 우울한 정서가 낮아진다고 나타 났다(Heo, 2015; Mo, 2018). 종합해보면 초기 청소년이 또래 및 교사와 유대감을 갖고 지지받는다고 느낄수록 이후 심리 정서 발달이 잘 이루어질 것이라고 예측된다(Yang \& Park, 2005).

Putnam (1995)은 개인적 차원에서 정서적으로 가까운 가족 이나 친구를 결속적 사회자본으로 구분했는데, 이러한 사회자 본은 사람들 간의 관계에서 개인이 특정 행위를 하도록 유도 하고 촉진한다(J. A. Seo, 2013). 부모의 관심과 적절한 통제는 자녀에게 심리적 안정감을 제공하고 자녀의 행동 양식에도 직 접적인 영향을 미칠 수 있다(Heo, 2015; Mo, 2018). 부모는 청
소년의 휴대전화 사용 습관을 형성하는 데 매우 중요한 역할 을 한다고 알려져 왔다(Heo, 2015; Y.-S. Kim, 2019; Mo, 2018). 부모와 친밀한 관계를 맺고 일상생활에 적절한 관심과 감독 을 받을 때 청소년의 휴대전화의존은 감소한다고 보고되었 다(Chang, Song, \& Cho, 2012). 반면 부모와 의사소통에 문제 가 있거나(A.-R. Lee \& Lee, 2012) 충분한 보살핌과 애정을 받 지 못하는 청소년은 휴대전화에 더욱 의존하는 양상을 보였다 (Bae, 2014; W. K. Lee, Rhee, Kim, \& Kim, 2020; Woo, 2013).

또래와 교사는 초기 청소년기의 휴대전화의존에 영향을 미 치는 주요한 사회자본이다(Chang et al., 2012; Y.-S. Kim, 2019; Woo, 2013). 일반적으로 교사와 관계가 좋고 학교생활에 적 응을 잘하는 청소년은 휴대전화의존이 낮다는 결과가 일관되 게 나타나고 있다(Chang et al., 2012). 한편 또래변인은 청소년 의 휴대전화의존 연구에서 상반되는 결과를 보이기도 한다. 국내 패널데이터를 활용한 몇몇 실증적 연구에서 또래애착과 휴대전화의존이 정적 관계가 있는 것으로 나타났는데(J.-H. $\mathrm{Kim}, 2012)$, 이러한 결과는 청소년이 또래관계를 원만하게 유 지하기 위해서 휴대전화를 자주 이용하기 때문이라고 해석되 었다(Sung, 2008). 그러나 한편으로 휴대전화를 과다하게 사용 하는 청소년은 또래관계의 질이 좋지 않다(J.-S. Lee \& Myung, 2007)고 보고되고 있는 점을 고려해볼 때 또래관계가 휴대전 화의존에 미치는 영향을 종단적 관점에서 면밀히 살펴볼 필요 가 있다. 본 연구에서는 사회자본이론을 바탕으로 또래 및 교 사와 긍정적인 관계를 형성할 때 청소년은 심리적 안녕감을 갖고 이는 이후 휴대전화의존을 낮추는 요인으로 작용할 것이 라는(Hwang, Cho, \& Hyun, 2016) 가설을 검증하고자 한다.

앞서 살펴본 바와 같이 청소년의 사회자본 내의 하위 변인 은 복합적인 관계 안에서 종단적 시점에 따라 청소년의 행동 및 정서 문제에 영향을 미칠 것으로 예상된다. 그러나 지금까 지 다수의 연구는 청소년의 미시체계 내의 사회자본을 통합적 관점에서 분석하지 못하였고, 주로 단일 시점에서 횡단 분석 을 수행하였다는 한계가 있다(Heo, 2015). 따라서 본 연구에서 는 초기 청소년의 부모·또래·교사관계를 하위요인으로 구성 하여 사회자본을 잠재변수로 설정하였다. 이로써 사회자본 하 위요인의 측정오차를 줄이고 최종적으로 초기 청소년의 사회 자본이 휴대전화의존과 우울에 미치는 영향력과 구조관계를 명확하게 검증하고자 하였다.

최근 한국아동.청소년패널조사(Korea Children and Youth Panel Survey [KCYPS]) 자료를 이용하여 초기 청소년의 휴대전 화의존이 어떠한 양상으로 변화하는지를 규명하고자 하는 종 단연구가 꾸준히 수행되고 있다. Hwang 등(2016)은 KCYPS 초 
4 패널을 이용하여 초5부터 중 1 까지 휴대전화의존을 선형변 화 모형으로 추정하였다. 이후 J. Y. Lee와 Chung (2018)의 연 구에서도 휴대전화의존이 초6에서 중3까지 지속해서 증가한 다고 보고했다. 가장 최근에 수행된 Y. Cho (2019)의 연구 또한 초4부터 중1까지 휴대전화의존의 추이를 선형변화 모형으로 추정하여 살펴보았다. 반면 초4에서 고1까지 휴대전화의존의 변화궤적을 분석한 K. Kim, Jo와 Song (2018)은 초4부터 중1까 지 휴대전화의존은 꾸준히 증가하다가 이후에는 일정한 수준 으로 유지된다고 밝혔다. 이와 같이 동일한 KCYPS 자료를 이 용하였으나 연구자가 선택한 변화궤적 모형에 따라 초기 청소 년의 휴대전화의존 변화 양상을 해석하는 데 차이가 있다. 이 러한 상이한 연구결과와 해석은 초기 청소년의 휴대전화의존 을 이해하고 구체적인 지원을 제공할 때 한계를 가지고 있다. 따라서 본 연구에서는 초기 청소년기에 해당하는 초등학교 5 학년부터 중학교 2학년까지 청소년의 휴대전화의존 변화를 경쟁모형 비교를 통하여 명확히 밝히고자 하였다.

이상의 논의를 종합하여 본 연구에서는 휴대전화의존이 높 아질 것으로 예상되는 초기 청소년기의 휴대전화의존의 변화 양상을 분석하고, 사회자본과 휴대전화의존이 청소년의 우울 을 예측할 수 있다는 이론적 모형을 검증하고자 한다. 사회자 본과 휴대전화의존의 변화 양상이 이후 청소년 우울에 미치는 구조적 관계를 밝혀낸다면 이후 청소년의 심리.정서적 문제를 예방하는 데 적극적으로 개입할 수 있을 것이다. 이에 본 연구 에서 규명하고자 하는 연구문제는 다음과 같다.

\section{연구문제 1}

초기 청소년기(초등학교 5학년 중학교 2학년) 휴대전화의 존도의 변화 궤적은 어떠한가?

\section{연구문제 2}

초기 청소년기의 사회자본(부모, 또래, 교사관계), 휴대전화의 존도의 변화 궤적 및 우울 간의 종단적 구조관계는 어떠한가?

\section{Methods}

\section{연구대상}

본 연구는 한국청소년정책연구원에서 실시한 한국아동.청소 년패널조사(KCYPS, 2010) 중 초등학교 4학년 패널 2,378명 의 2-5차 연도(초5 중2) 자료를 활용하였다. 표본은 2010년
전국 초등학교 4학년을 기준으로 다단계층화집락표집(multistage stratified cluster sampling)으로 선정되었다. 2010년 1차 연 도에 포함된 패널 아동은 총 2,378명이었으며, 이후 조사대상 자 수가 점차 감소하여 본 연구에서 활용한 $2,3,4,5$ 차 연도에 포함된 최종 표본 수는 각각 2,264명(95.2\%), 2,219명(93.3\%), $2,092(88.0 \%), 2,070$ 명(87.0\%)이었다. 본 연구의 연구모형에 따라 휴대전화의존도는 $2,3,4,5$ 차 연도 사회자본(부모, 또래, 교사관계)은 2 차 연도, 우울은 5 차 연도 자료를 사용하였다. 2 차 연도를 기준으로 분석에 포함된 연구대상의 성별은 남아 $52.3 \%(1,183$ 명 $)$, 여아 $47.7 \%(1,081$ 명 $)$ 이었다.

\section{연구도구}

\section{휴대전화의존도}

휴대전화의존도는 S. H. Lee 등(2002)이 개발한 척도를 참고하 여 구성한 한국아동.청소년패널 자료를 그대로 사용하였다. "점점 더 많은 시간을 휴대전화를 사용하며 보내게 된다." "휴 대전화를 가지고 나가지 않으면 불안하다.", "휴대전화로 이것 저것 하다 보면 시간 가는 줄 모른다.", “휴대전화가 없으면 불 편해서 살 수 없다.” 등 총 7문항으로 구성되어 있다. 각 문항은 4점 리커트 척도(매우 그렇다[1점] 전혀 그렇지 않다[4점])로 점 수가 높을수록 휴대전화의존도가 높음을 의미하도록 역 채점 하였다. $2,3,4,5$ 차 연도의 휴대전화의존도 문항 간 신뢰도 계수 Cronbach's $\alpha$ 값은 각각 $.88, .89, .90, .88$ 로 양호한 수준이었다.

$$
\text { 우울 }
$$

우울은 간이정신진단검사(K. I. Kim, Kim, \& Won, 1984) 10 문 항으로 한국아동.청소년패널에서 측정한 문항을 그대로 사용 하였다. 우울 척도는 "불행하다고 생각하거나 슬퍼하고 우울 해한다.”, “외롭다.” "모든 일에 관심과 흥미가 없다.” 등의 문 항으로 구성되어 있다. 각 문항은 4점 리커트 척도(매우 그렇 다[1점] 전혀 그렇지 않다[4점])이며, 자기보고 방식으로 측 정되었다. 점수가 높을수록 우울함을 더 자주 느낀다고 해석 하기 위해서 전체 문항을 역 채점하였다. 5 차 연도 우울 척도 의 문항 간 신뢰도 계수 Cronbach's $\alpha$ 는 .91이었다.

\section{사회자본}

사회자본은 개인 수준에서 쉽게 접근할 수 있고 지원을 받을 
수 있는 사회적 관계(Poortinga, 2006)를 통해 받는 사회적 유 대, 상호 간의 호혜(reciprocity), 사회적 지지 등을 포함하는 개 념이다(Bae, 2018; Coleman, 1990; Putnam, 1993). 본 연구에서 는 청소년이 매일 반복되는 일상에서 맺는 사회적 관계를 청 소년 개인 수준의 사회자본으로 간주하였다. 이를 살펴보기 위해 부모.또래·교사관계를 하위요인으로 하는 사회자본을 잠재변수로 구성함으로써 청소년이 일상에서 경험하는 사회 적 관계를 폭넓게 포함하였다. 사회자본을 잠재변수로 구성하 면 측정오차를 고려한 분석이 가능하므로 변인 간의 구조관계 를 더욱 정확하게 도출해낼 수 있다는 장점이 있다.

부모관계는 Huh (2000)의 양육방식 척도 하위요소 중 방임 에 해당하는 4 문항을 사용하여 측정되었다. "다른 일(직장이나 바깥일)보다 나를 더 중요하게 생각하신다.”, "내가 학교에서 어 떻게 생활하는지 관심을 갖고 물어보신다.”, “내 몸이나 옷, 이불 등이 깨끗하도록 항상 신경 쓰신다.", "내가 많이 아프면 적절한 치료를 받게 하신다."는 내용으로 구성되어 있다. 각 문항은 4점 리커트 척도(매우 그렇다[1점] 전혀 그렇지 않다[4점])이며, 자 기보고 방식으로 측정되었다. 부모관계 점수가 높을수록 부모 가 자녀를 중요하게 생각하고 관심을 보이며, 자녀는 부모로부 터 지원을 받고 있다고 인식한다는 의미로 해석하기 위하여 각 문항을 역 채점하여 평균을 산출하였다. 2 차 연도의 부모관계 문항 간 신뢰도 계수 Cronbach's $\alpha$ 는 .77로 나타났다.

또래관계와 교사관계는 학교생활 적응 척도(Min, 1991)에서 또래관계와 교사관계에 해당하는 하위 영역이다. 학교생활 적 응 척도에서 또래관계는 총 5 문항으로 구성되어 있는데 확인적
요인분석을 한 결과 요인부하량이 현저하게 낮은 "친구가 하는 일을 방해한다.”는 1 문항을 제외하고, 나머지 4문항으로 또래 관계 변수를 구성하였다. 예시 문항으로 “우리 반 아이들과 잘 어울린다." "놀이나 모둠 활동을 할 때 친구들이 내 말을 잘 따 라준다.” 등이 있다. 각 문항은 4점 리커트 척도(매우 그렇다 $[1$ 점] 전혀 그렇지 않다[4점])이며, 자기보고 방식으로 측정되었 다. 각 문항을 역 채점하였고, 따라서 또래관계 점수가 높을수 록 학교에서 친구와의 관계가 원만하고, 결속감과 지지를 받는 긍정적인 관계를 형성하고 있다고 해석할 수 있다. 2 차 연도의 또래관계 4문항 간 신뢰도 계수 Cronbach's $\alpha$ 는 .71로 나타났다.

교사관계는 총 5문항으로, “선생님을 만나면 반갑게 인사 한다.", "선생님과 이야기 하는 것이 편하다.", "우리 선생님께 서는 나에게 친절하시다." 등의 문항으로 측정되었다. 각 문 항은 4점 리커트 척도(매우 그렇다[1점] 전혀 그렇지 않다[4 점])이며, 자기보고 방식으로 측정되었다. 각 문항은 역채점하 였으며, 따라서 교사관계에서 점수가 높을수록 학교 맥락에서 교사와 사회.정서적 유대가 높다고 해석할 수 있다. 2차 연도 의 교사관계 문항 간 신뢰도 계수 Cronbach's $\alpha$ 는 .86으로 양호 한 수준으로 나타났다.

\section{연구모형 및 자료 분석}

본 연구에서 분석하고자 하는 연구가설 모형은 Figure 1과 같 다. 초등학교 5학년부터 중학교 2학년에 이르기까지 초기 청 소년의 휴대전화의존도 변화궤적의 양상과 개인차를 알아보

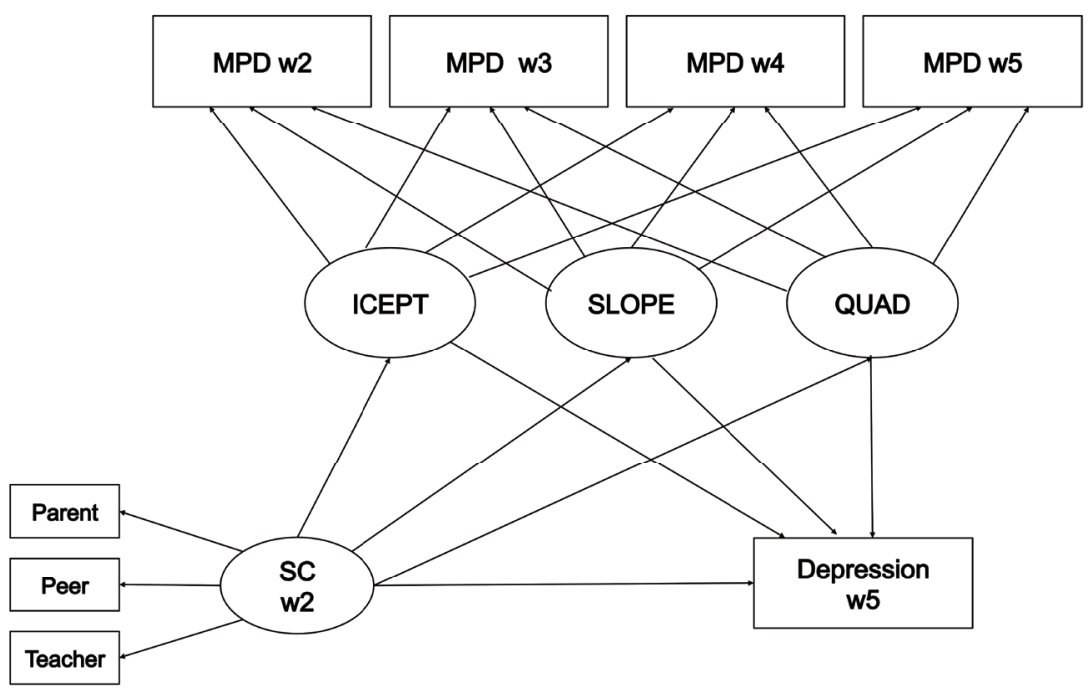

Figure 1. The hypothesized model.

$\mathrm{SC}=$ social capital $\mathrm{MPD}=$ mobile phone dependency; ICEPT = intercept; SLOPE = linear slope; QUAD = quadratic slope. 
Table 1

Descriptive Statistics of Major Variables

\begin{tabular}{|c|c|c|c|c|c|}
\hline Variables & $N$ & $M$ & $S D$ & Skewness & Kurtosis \\
\hline \multicolumn{6}{|l|}{ Mobile Phone Dependency (MPD) } \\
\hline MPD of $5^{\text {th }}$ grade $(w 2)$ & 1892 & 1.79 & .65 & .95 & .74 \\
\hline MPD of $6^{\text {th }}$ grade (w3) & 1995 & 2.05 & .71 & .50 & -.17 \\
\hline MPD of $7^{\text {th }}$ grade $(w 4)$ & 1972 & 2.24 & .71 & .34 & -.22 \\
\hline MPD of $8^{\text {th }}$ grade (w5) & 1969 & 2.23 & .67 & .31 & .04 \\
\hline \multicolumn{6}{|c|}{ Social Capital (SC) of $5^{\text {th }}$ grade (w2) } \\
\hline Parent relationship & 2264 & 3.44 & .55 & -.84 & .66 \\
\hline Peer relationship & 2264 & 3.10 & .54 & -.41 & .26 \\
\hline Teacher relationship & 2264 & 3.12 & .66 & -.51 & -.02 \\
\hline Depression of $8^{\text {th }}$ grade (w5) & 2070 & 1.78 & .58 & .47 & -.13 \\
\hline
\end{tabular}

Note. The number of cases differs because missing values are excluded for each variable; Social capital is a latent variable composed of the relationship with parents, peers, and teachers.

Table 2

Correlations of Analyzed Variables

$\begin{array}{lllllllll}1 & 2 & 3 & 4 & 5 & 6 & 7 & 8\end{array}$

1. MPD of $5^{\text {th }}$ grade (w2)

2. MPD of $6^{\text {th }}$ grade $(w 3)$

3. MPD of $7^{\text {th }}$ grade $(w 4)$

4. MPD of $8^{\text {th }}$ grade (w5)

5. Parent relationship (w2)

6. Peer relationship (w2)

7. Teacher relationship (w2)

$-$

8. Depression of $8^{\text {th }}$ grade $(w 5)$

${ }^{*} p<.05 .{ }^{* *} p<.01$.

기 위해 잠재성장모형(latent growth modeling)을 설정하였다.

이를 바탕으로 휴대전화의존도의 변화궤적, 초등학교 5학년

시기 청소년 개인이 가진 사회자본, 그리고 중학교 2학년 시기

우울 간의 구조관계를 검증하고자 선행연구를 토대로 구조모

형을 설정하여 분석하였다.

자료는 SPSS 20.0 (IBM Co., Armonk, NY)과 AMOS 20.0 (IBM Co., Armonk, NY) 프로그램을 사용하여 분석하였다. 먼 저, 연구대상의 특성 및 분포를 살펴보기 위해 기술통계 및 상 관분석을 실시하였다. 연구모형의 적합도를 판단하기 위하 여 $\chi^{2}$ 과 함께 CFI, TLI, RMSEA 값을 함께 고려하였다. $\chi^{2}$ 값 은 영가설이 너무 쉽게 기각되고, 표본의 크기가 커지면 유의 하게 나타나는 경향이 있어서(Kline, 2005), 본 연구에서는 표 본크기에 민감하게 영향을 받지 않는 적합도지수인 CFI, TLI, RMSEA 값을 함께 고려하였다. 일반적으로 CFI, TLI는 .95 이 상, RMSEA는 .05 이하일 때 모형의 적합도가 좋음을 의미하
며, CFI, TLI는 .90 이상, RMSEA는 .07 이하일 경우 모형의 적 합도가 양호하다고 본다(Hong, 2000). 패널데이터의 특성상 결측값이 존재하므로, 결측값을 처리하기 위하여 관찰된 변인 의 모든 정보를 활용하는 완전정보최대우도법(full information maximum likelihood)을 사용하였다.

\section{Results}

\section{기술통계 및 상관분석}

본 연구에서 활용한 완전정보최대우도법의 기본 가정으로 정규분포를 충족하는지 확인하고자 왜도(skewness)와 첨도 (kurtosis) 값을 살펴보았다. 그 결과 왜도, 첨도 값이 모두 \pm 1 미만으로 일반적 기준인 왜도 \pm 2 미만, 첨도 \pm 7 에 충분히 부합 
Table 3

Model Fit and Estimated Means of Growth Factors

\begin{tabular}{|c|c|c|c|c|c|c|c|}
\hline Model & Growth factor & $\chi^{2}$ & $d f$ & $p$ & TLI & CFI & $\begin{array}{l}\text { RMSEA } \\
(90 \% \mathrm{CI})\end{array}$ \\
\hline Non-change model & Intercept $=2.09^{* * *}$ & 915.99 & 8 & .000 & .063 & .251 & $\begin{array}{c}.219 \\
(.207, .231)\end{array}$ \\
\hline Linear model & $\begin{array}{ll}\text { Intercept } & =1.84^{* * *} \\
\text { Slope } & =.15^{* * *}\end{array}$ & 171.87 & 5 & .000 & .725 & .862 & $\begin{array}{c}.118 \\
(.104, .134)\end{array}$ \\
\hline
\end{tabular}

${ }^{* * *} p<.001$.

하였다(West, Finch, \& Curran, 1995). 주요 측정변수의 기술통 계 결과는 아래 Table 1 과 같다.

초기 청소년의 휴대전화의존도 평균은 초등학교 5학년인 2 차 연도에 1.79 로 시작하여 3차 연도 $2.05,4$ 차 연도 2.24 로 점 차 증가하다 중학교 2학년인 5차 연도에 2.23으로 미약하지 만 감소하는 추세로 나타났다. 잠재변인으로 구성한 사회자본 의 평균은 초등학교 5학년인 2차 연도에 부모관계 3.44 , 또래 관계 3.10, 교사관계 3.12로 나타났다. 모두 4점 리커트 척도로 측정된 변수임을 고려하면, 연구대상 초기 청소년의 사회자본 평균은 비교적 높은 편인 것으로 볼 수 있다. 중학교 2학년 시 기 우울의 평균은 1.78 이었다. 측정변수 간 상관관계는 Table 2 에 제시하였다.

휴대전화의존도 2-5차 연도 값은 모두 정적 상관이 있었으 며, 시간상 밀접한 연도일수록 휴대전화의존도 간 상관이 더 높게 나타났다 $(p<.01)$. 사회자본의 하위 측정변수인 부모관 계 2 차 연도 평균은 휴대전화의존도 $2,3,4,5$ 차 연도 평균과 각각 낮은 부적 상관이 나타났으며(2차: $r=-.11 ; 3$ 차: $r=-.07$; 4차: $r=-.02$; 5차: $r=-.06, p s<.05), 5$ 차 연도 우울과도 낮은 수준의 부적 상관이 있었다 $(r=-.17, p<.01)$. 부모관계 2 차 연 도 평균은 같은 연도의 또래관계 $(r=.38, p<.01)$, 교사관계 $(r$ $=.32, p<.01)$ 와 중간 정도의 정적 상관을 보였다. 또래관계는 3,4 차 연도 휴대전화의존도와 통계적으로 유의한 상관이 없 었으나, 2 차 연도의 휴대전화의존도 $(r=-.04, p<.05)$ 그리고 5 차 연도의 휴대전화의존도 $(r=-.06, p<.01)$ 와 매우 낮은 수준 의 부적 상관이 있었다. 교사관계 역시 휴대전화의존도 및 우 울과 낮은 수준의 부적 상관을 나타내었다( 2 차: $r=-.08 ; 3$ 차: $r=-.05 ;$ 4차: $r=-.02 ; 5$ 차: $r=-.06 ; p<.05, p<.01) .5$ 차 연도 우울 평균은 휴대전화의존도 2-5차 연도와 모두 정적 상관이 있었고(2차: $r=.11 ; 3$ 차: $r=.15 ; 4$ 차: $r=.20 ; 5$ 차: $r=.33, p s$ $<.01), 5$ 차 연도 우울 평균은 2 차 연도 사회자본의 하위변수인
부모관계 $(r=-.17, p<.01)$, 또래관계 $(r=-.15, p<.01)$, 교사관 계 $(r=-.08, p<.01)$ 와 부적 상관이 있었다.

\section{휴대전화의존도 변화궤적}

초등학교 5학년에서 중학교 2학년까지 휴대전화의존도가 변 화하는 형태를 추정하는 최적의 모형을 찾기 위해 무변화모 형, 선형모형, 비선형모형 적합도의 통계치를 산출하였다. 무 변화모형은 청소년의 휴대전화의존도에 변화가 없다고 가정 하며, 선형모형은 휴대전화의존도가 일정하게 높아지거나 낮 아질 것을 가정한다. 비선형모형의 경우 휴대전화의존도의 변 화가 일정하지 않다고 가정하는데, 본 연구에서는 선행연구 결과를 바탕으로 휴대전화의존도 변화량이 점차 증가하거나 감소하는 이차곡선 형태를 보일 것이라고 설정하였다.

Table 3에 제시한 바와 같이, 휴대전화의존도 변화의 잠재 성장모형 적합도는 $\chi^{2}$ 값과 TLI, CFI, RMSEA 값을 기준으로 살펴보고 모형별 변화요인의 예측평균을 살펴보았다. 각 모형 에서 초기치, 변화율, 이차항을 잠재요인으로 하나씩 추가하 여 설정하였다. 초기치에서 2-5차 연도의 휴대전화의존도로 가는 경로는 모두 1 로, 변화율의 경로는 각각 $0,1,2,3$ 으로, 이 차항의 경로는 변화율의 제곱으로 각각 $0,1,4,9$ 로 고정하여 분석하였다.

휴대전화의존도 변화궤적을 더욱 잘 설명하는 모형을 선 택하기 위하여 적합도와 변화요인의 예측평균을 종합적으로 고려한 결과, 비선형모형이 가장 타당한 것으로 나타났다. 휴 대전화의존도의 변화궤적은 비선형모형인 이차함수모형에 서 $\mathrm{TLI}=.949, \mathrm{CFI}=.995, \mathrm{RMSEA}=.051$ 로 매우 좋은 적합도 로 나타났다(Hong, 2000; Steiger, 1990). 또한 초기치(1.78, $p<$ $.001)$ 와 변화율(.36, $p<.001)$, 이차항(-.07, $p<.001)$ 의 예측평 균이 모두 유의하였다. 최적 모형으로 나타난 비선형모형의 
Table 4

Estimates of MPD Latent Growth Model: Quadratic Model

\begin{tabular}{lccc}
\hline & Intercept & Slope & Quadratic slope \\
\hline Intercept & $1.780^{* * *}$ & $.358^{* * *}$ & $-.068^{* * *}$ \\
\hline Variance & $.339^{* * *}$ & $.255^{* * *}$ & $.014^{* * *}$ \\
\hline Covariance & & Icept $\leftrightarrow$ Slope $=-.177(-.603)^{* * *}$ & \\
& & Icept $\leftrightarrow$ Quad $=.033(.474)^{* *}$ & \\
& & Slope $\leftrightarrow$ Quad $=-.057(-.943)^{* * *}$ & \\
\hline
\end{tabular}

Note. Standardized correlation coefficient in parentheses.

${ }^{* *} p<.01 .{ }^{* * *} p<.001$.

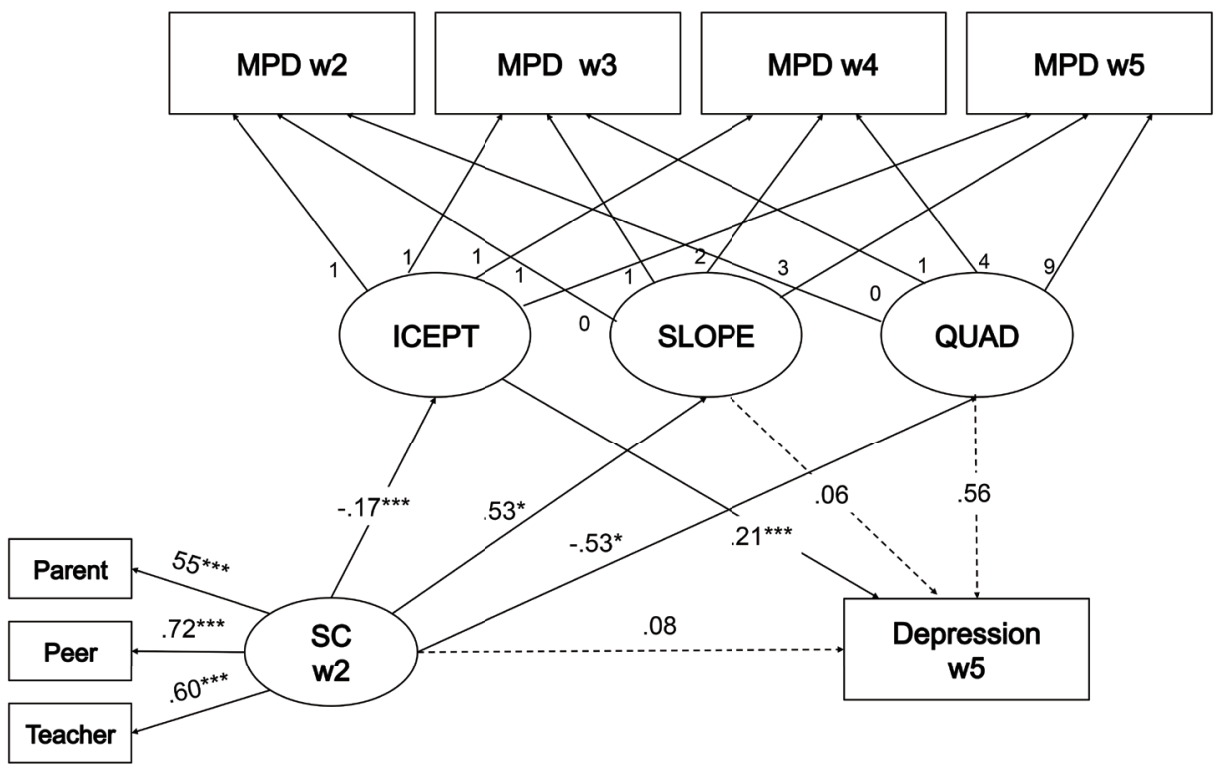

Figure 2. Structural relationships among MPD trajectory, social capital and depression.

Model fit: $\chi^{2}=120.893(d f=16, p<.001)$; TLI = .903; CFI $=.957$; RMSEA $=.053$ (90\% CI [.044-.061]); The path coefficients shown in the model are standardized regression coefficients.

${ }^{* * *} p<.001$.

모수추정치는 Table 4에 제시하였다.

휴대전화의존도 변화궤적의 초기치 예측평균은 1.78 이고, 변화율의 예측평균은 .36이며, 이차항은 -.07로 통계적으로 모 두 유의하였다. 즉, 초등학교 5학년부터 중학교 2학년 시기에 이르기까지 청소년의 휴대전화의존도는 1.78 에서 시간의 흐름 에 따라 매년 .36씩 평균적으로 유의하게 증가하되, 증가율은 .07씩 감소하는 것으로 해석할 수 있다. 휴대전화의존도의 초 기치와 변화율, 이차항의 분산 또한 모두 유의하게 나타나, 휴 대전화의존도 변화궤적의 출발점이나 증가율, 증가율의 변화 모두에 있어서 개인차가 유의함을 알 수 있었다. 공분산을 살 펴보면 초등학교 5학년 시기휴대전화의존도가 높을수록 휴 대전화의존도의 증가는 천천히 일어났으며(초기치 $\leftrightarrow$ 변화율 ; $r=-.60, p<.001)$, 변화율이 높아질수록 증가 추세는 더 느리
게 나타났다고 해석할 수 있다(변화율 ↔ 이차항 ; $r=-.94, p<$ .001).

\section{휴대전화의존도 변화궤적, 우울 및 사회자본의 구조관계}

본 연구에서 설정한 변인 간 영향력을 알아보기 위해 초기 청 소년의 휴대전화의존도 변화궤적, 우울 및 사회자본 간 구조 관계를 Figure 2와 같이 설정하였다. 구조모형의 모형적합도는 $\chi^{2}=120.893(d f=16, p<.001)$, TLI $=.903$, CFI = .957, RMSEA $=.053(90 \% \mathrm{CI}[.044 \sim .061])$ 으로 모형의 적합도가 좋은 것으 로 나타났다.

초기 청소년의 휴대전화의존도 변화궤적, 사회자본 및 우 
Table 5

Estimates of Path Coefficient and Parameters for Structural Model

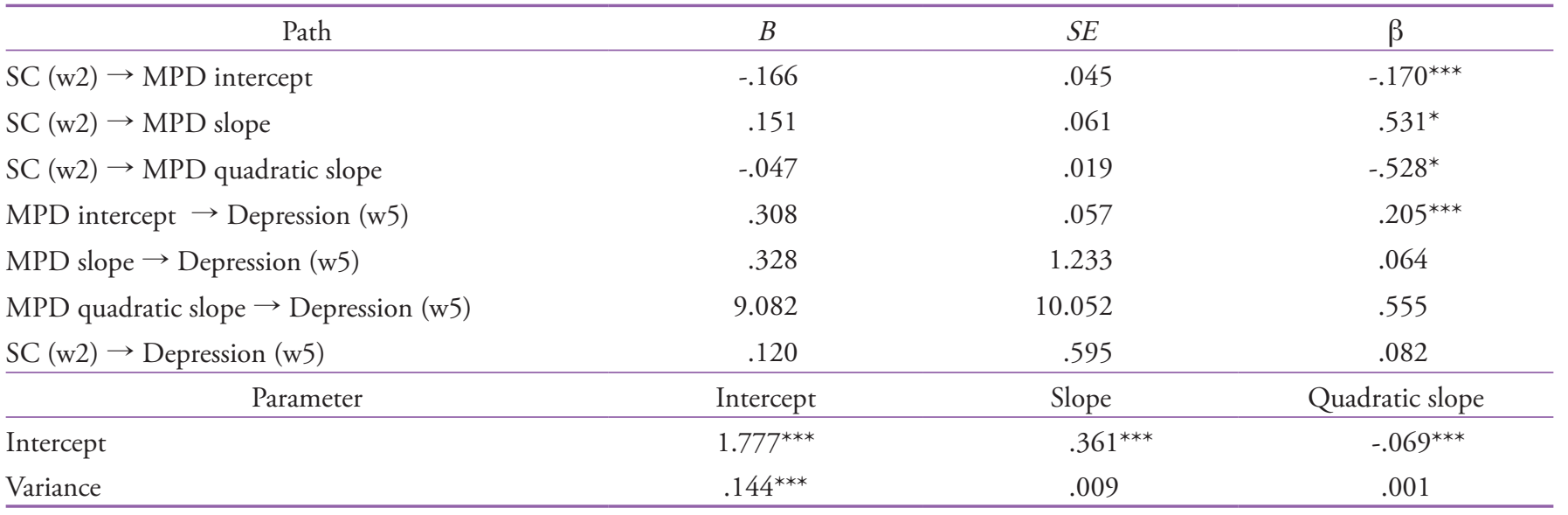

Note. SC = social capital; $\mathrm{MPD}=$ mobile phone dependency.

${ }^{*} p<.05 .{ }^{* * *} p<.001$.

울 간 영향력은 Table 5 와 같다. 먼저 초등학교 5 학년 시기의 사회자본이 초등학교 5학년에서 중학교 2학년까지 휴대전화 의존도 변화궤적에 미치는 영향력은 모두 유의하였다. 즉, 초 등학교 5학년 시기에 부모, 또래, 교사로부터 심리.정서적 지 원을 더 많이 받는다고 느낄수록 휴대전화의존도의 초기치는 더 낮았으며 $(\beta=-.170, p<.001)$, 증가율은 더욱 높았으나 $(\beta=$ $.531, p<.05)$ 시간이 지날수록 증가율의 변화추세는 더 느리 게 나타났다 $(\beta=-.528, p<.05)$. 휴대전화의존도의 변화궤적이 중학교 2학년 시기의 우울에 미치는 영향력을 살펴보았을 때, 휴대전화의존도 변화궤적의 초기치만이 유의한 영향력을 갖 는 것으로 나타났다 $(\beta=.205, p<.001)$. 즉, 초등학교 5 학년 때 휴대전화의존도가 높을수록 중학교 2 학년 시기의 우울감이 유의하게 높다는 것을 의미한다. 초등학교 5학년 시기의 사회 자본이 중학교 2학년 시기의 우울에 미치는 직접적인 영향력 은 유의하지 않았으며, 휴대전화의존도의 초기치를 통하여 간 접적으로 우울에 영향력을 미치는 것으로 나타났다. Sobel test 를 이용한 간접효과의 유의성 검정 결과, 휴대전화의존도 초 기치의 매개효과는 통계적으로 유의한 것으로 나타났다 $(Z=$ $-3.85, p<.001)$.

또한 초등학교 5학년 시기의 사회자본과 중학교 2학년 시 기의 우울이 포함된 구조모형에서, 휴대전화의존도 변화궤적 의 초기치(1.78, $p<.001)$, 변화율(.36, $p<.001)$, 이차항 $(-.07, p$ $<.001)$ 의 평균은 모두 유의하여 시간이 지날수록 증가율이 점 차 감소하는 이차함수 곡선의 형태를 보였다. 성장요인 중 초 기치의 분산(.14, $p<.001)$ 만 유의하게 나타나, 초기치에서만 여전히 개인차가 존재함을 확인할 수 있었다.

\section{Discussion}

본 연구는 휴대전화 보유율과 이용 시간이 급격히 증가하는 시기인 초기 청소년기에 주목하여, 초등학교 5학년부터 중학 교 2학년까지의 휴대전화의존도 변화 양상을 확인하고, 이를 바탕으로 휴대전화의존도의 변화궤적, 초등학교 5학년 시기 의 사회자본(부모관계, 또래관계, 교사관계), 그리고 중학교 2 학년 시기 우울 간의 구조관계를 검증하였다. 본 연구의 주요 결과를 종합하고 논의를 끌어내면 다음과 같다.

첫째, 초등학교 5학년부터 중학교 2학년에 이르기까지 초 기 청소년의 휴대전화의존도 변화 양상은 시간이 흐름에 따라 증가하지만, 증가 추세는 점차 감소하는 이차함수의 형태로 나 타났다. 또한 초기치, 변화율, 이차항의 분산이 모두 유의한 것 으로 나타나, 초기 청소년기 휴대전화의존도의 변화궤적에는 개인차가 있는 것을 확인할 수 있었다. 특히, 초등학교 5학년 시기에 또래보다 휴대전화의존도가 높았던 아동은 중학교 2 학년 때까지 학년이 올라갈수록 휴대전화의존도가 점차 증가 하지만 휴대전화의존도가 낮았던 아동에 비해 비교적 천천히 증가하는 경향을 보였다. 반면 초등학교 5학년 시기에 또래보 다 휴대전화의존도가 낮았던 아동은 중학교 2학년 때까지 학 년이 올라갈수록 휴대전화의존도가 비교적 빠른 증가를 하는 것으로 나타났다. 이는 초등학교 고학년 시기에 휴대전화의존 도에 차이가 있다 하더라도 초기 청소년기를 거치면서 일정 수 준의 휴대전화의존을 보인다는 것을 알 수 있었다. 이러한 결 과는 선행연구들에서 초등학교 고학년에서 중학교에 이르기 까지 휴대전화의존도가 대체로 증가하는 경향을 보고한 것과 
는 일치하지만, 지속해서 선형 증가를 한다는 연구(Hwang et al., 2016; J. Y. Lee \& Chung, 2018)와는 다르게 시간이 흐를수록 증가율이 낮아지는 양상을 보인다는 것을 확인하였다.

한편, 본 연구에서 초등학교 5학년부터 중학교 2학년에 이 르기까지 휴대전화의존도의 평균은 $1.79 \sim 2.24$ 의 범위에 해 당하여 4점 척도에서 중간 정도의 범위인 것으로 나타났다. 본 연구와 동일한 척도를 사용하여 초기 청소년기 휴대전화의존 도의 변화를 분석한 선행연구의 결과를 살펴보면, 초등학교 4 학년부터 고등학교 1학년 시기까지 휴대전화의존도의 변화를 살펴본 연구(K. Kim et al., 2018)에서는 휴대전화의존도의 평 균이 1.79 2.25로 중학교 1학년 이후 휴대전화의존도가 거의 변화하지 않고 유지되는 것으로 나타났다. 또한 초등학교 고 학년 시기 지역아동센터 아동의 휴대전화의존도 변화를 살펴 본 연구(Nam \& Ha, 2019)에서도 초등학교 4학년에서 6학년 시점에 이르기까지의 평균은 $1.94 \sim 2.09$ 로 중간 정도 수준으 로 나타났다. 이러한 결과들은 초기 청소년기에 휴대전화의존 도가 뚜렷한 증가 추세를 보이지만 이 시기의 휴대전화의존도 가 특별히 위험한 수준은 아니라는 것을 의미한다. 즉, 평균 점 수보다는 시간에 따른 변화와 개인차에 초점을 맞추어 살펴볼 필요가 있다는 점을 시사한다.

둘째, 초등학교 5학년 시기의 사회적 관계, 즉 부모와의 관 계, 또래관계, 교사관계는 휴대전화의존도의 변화궤적에 유의 한 영향을 미치는 것으로 나타났다. 초등학교 5학년 때 부모, 또래, 교사로부터 심리적, 정서적 지원을 더 많이 받는다고 느 낄수록 휴대전화의존도의 초기치는 더 낮았으며, 시간이 지날 수록 증가율의 변화추세는 더 느리게 나타났다. 이 결과는 부 모, 또래, 교사와의 관계가 지지적이라고 느끼는 경우, 초등학 교 5학년 시기의 휴대전화의존도뿐만 아니라 이후 중학교 2학 년 때까지의 휴대전화의존도를 낮추는 데 영향을 미칠 수 있음 을 의미한다. 선행연구에서 또래관계가 휴대전화의존도에 미 치는 영향에 관한 연구결과는 일관되지 않았는데, 본 연구결과 는 또래관계를 긍정적으로 인식할수록 휴대전화의존도가 더 낮았다는 결과(Hwang et al., 2016; J.-S. Lee \& Myung, 2007)를 지지하였으며, 또래관계를 포함하여 자신을 둘러싼 사회적 관 계에서 편안함과 유대감을 느끼는 것이 휴대전화의존도의 변 화에 긍정적인 영향을 미칠 수 있다는 점을 확인하였다.

셋째, 초기 청소년기의 휴대전화의존도 변화궤적 중 초기치 만이 중학교 2 학년 시기의 우울을 유의하게 예측하는 요인이었 다. 즉, 초등학교 5학년 시기의 휴대전화의존도가 중학교 2학년 시기의 우울을 예측한 결과라고 할 수 있다. 휴대전화의존도의 변화궤적을 살펴보았을 때, 초등학교 고학년 시기에 휴대전화
의존도가 보다 높았던 경우 휴대전화의존도가 낮았던 경우에 비해 시간에 따른 증가율은 낮았으나, 초기 청소년기 동안 지속 해서 휴대전화의존도가 또래에 비해 높은 수준으로 유지되었 기 때문에 중학교 2학년 시기의 우울에 영향을 미친 것으로 해 석할 수 있다. 청소년을 대상으로 휴대전화의존도와 우울 간의 관계를 규명한 연구들에서는 관계의 방향에 대하여 연구결과 들이 혼재되어 있으며, 휴대전화의존과 우울이 매우 밀접한 관 련이 있음을 시사한다. 본 연구의 결과는 휴대전화의존이 우울 에 영향을 미친다는 이론적 모형(Elhai et al., 2017; Lapierre et al., 2019)을 지지하는 결과라고 볼 수 있다. 즉, 초기 청소년기에 급 격히 증가하는 휴대전화 보유율과 이용 시간은 휴대전화의존 의 위험을 높이고, 초기 청소년의 심리.정서적 문제를 야기할 수 있다는 것으로 해석된다. 그러나 휴대전화의존도의 초기치만 이 이후의 우울에 영향을 미쳤으며 변화율은 유의한 영향을 미 치지 않았던 것을 고려할 때, 후속 연구에서는 초등학교 5학년 시기의 우울을 포함하여 분석한다면 휴대전화의존도와 우울 간의 관계를 더욱 명확하게 검증할 수 있을 것이다.

넷째, 초기 청소년의 사회자본이 우울에 미치는 직접효과 는 유의하지 않았으나, 휴대전화의존도의 초기치를 매개로 한 간접효과는 유의한 것으로 나타나 사회자본이 우울에 미치는 영향에 있어서 휴대전화의존도의 완전매개효과가 있음을 확 인하였다. 즉, 초기 청소년의 긍정적 사회자본이 우울에 대하 여 직접적인 보호요인으로 작용하기보다는 초등학교 시기 휴 대전화의존도를 낮춤으로써 이후의 우울 수준을 낮추는 간접 적인 보호요인임을 알 수 있다. 다시 말해, 일상에서 경험하는 부모, 또래, 교사와의 관계가 긍정적이지 않다고 평가하는 경 우에도, 미래의 우울 수준에 직접 영향을 미치는 것이 아니라 휴대전화의존도를 매개로 하여 장기적 관점에서 정서 문제로 나타날 수 있음을 의미한다. 초등학교 5학년 시기의 사회자본 과 휴대전화의존도가 중학교 2학년 시기의 우울과 관련된 중 요한 변인이라는 것을 밝힘으로써, 청소년의 심리.정서적 건 강에 관한 조기개입의 중요성을 확인하였다.

종합하면, 본 연구는 초기 청소년기의 휴대전화의존도 변 화궤적을 확인하고, 초등학교 5학년 시기에 평가한 부모, 또 래, 교사와의 관계의 질이 같은 시기의 휴대전화의존도를 매 개로 중학교 2 학년 시기의 우울에 영향을 미친다는 결과를 밝 혔다는 의의가 있다. 특히 초등학교 고학년 시기의 휴대전화 의존도에 주목할 필요가 있는데, 초등학교 5학년 때 휴대전화 의존도가 높았던 경우, 초기 청소년기 동안 휴대전화의존도가 또래에 비해 지속적으로 높은 수준으로 유지될 뿐만 아니라, 초등학교 5학년 때 경험하는 사회적 관계가 이후 중학교 2학 
년 시기의 우울 수준에 미치는 영향을 매개하기 때문이다. 따 라서 휴대전화의존이 청소년의 심리.정서적 건강에 미치는 영 향을 최소화하기 위해서는 휴대전화 보유율과 이용 시간이 증 가하기 시작하는 초등학교 고학년 시기(M. Seo, 2016)에 조기 중재가 필요함을 알 수 있다. 초등학교 고학년 시기에 휴대전 화 이용 시간 및 이용 유형을 확인하고, 휴대전화 이용이 일상 및 학업에 얼마나 영향을 미치는지 파악하여 휴대전화 사용을 조절할 수 있도록 부모와 교사의 관심과 지도가 필요하다. 또 한 본 연구의 결과는 초등학교 5학년 때 부모, 또래, 교사와의 사회적 관계를 긍정적이고 지지적이라고 지각하는 경우 휴대 전화의존도의 초기치가 더 낮게 나타나, 초기 청소년이 경험 하는 사회적 관계가 휴대전화의존도에 대한 중요한 보호요인 이 될 수 있다는 점을 시사하였다. 청소년의 휴대전화의존도 에 대한 예방적 개입을 위해서는 부모, 또래, 교사와의 관계 증 진을 통해 관계 속에서 긍정적인 정서 경험을 하고, 지지적인 상호 관계를 형성할 수 있도록 돕는 것에서 출발해야 할 것이 다. 모든 관계는 양방향의 상호작용을 기반으로 하므로, 이는 결국 청소년만의 문제가 아니라 가정과 학교에서 함께 관심을 기울이고 협력하여야 할 문제이다.

본 연구의 제한점을 바탕으로 후속 연구에 대한 제언을 제시 하면 다음과 같다. 본 연구에서는 초등학교 5학년 시기의 사회 자본이 같은 시기 휴대전화의존도를 매개로 하여 중학교 2학년 시기의 우울 수준에 영향력을 미친다는 것을 확인하였으나, 사 회자본이 측정된 시점과 우울이 측정된 시점 간의 차이로 인하 여 직접효과가 유의하지 않았을 가능성이 있고, 시간의 흐름에 따라 청소년이 경험하는 다양한 생활 사건이 미칠 수 있는 영 향력을 고려하지 못했다는 한계가 있다. 따라서 후속 연구에서 는 우울의 변화궤적을 함께 확인한다면 사회자본이 우울에 미 치는 장기적인 영향력을 더욱 명확하게 검증할 수 있을 것이다. 또한 본 연구에서는 초등학교 5 학년부터 중학교 2학년까지의 휴대전화의존도 변화에 초점을 두어 분석이 이루어졌는데, 더 어린 연령의 아동에서도 일상생활과 학업에서 휴대전화를 사 용하는 비중이 점차 높아지고 있으므로 학령초기 아동을 포함 한 종단분석이 이루어질 필요가 있다. 본 연구에서는 부모, 또 래, 교사와의 관계를 사회자본이라는 하나의 잠재변인으로 구 성하여 청소년이 일상에서 경험하는 사회적 관계가 미치는 영 향력을 더욱 정확하게 분석할 수 있었다. 그러나 대상과 특성이 뚜렷이 구분되는 각각의 관계들이 어떠한 영향력을 미치는지 확인하기 위해서는 심도 있는 비교 분석이 요구된다. 후속 연구 에서는 부모, 또래, 교사관계가 미치는 상대적 영향력을 확인함 으로써 초기 청소년의 휴대전화의존에 대한 예방적 개입 방안
을 보다 구체적으로 제시할 수 있을 것으로 기대한다.

\section{Notes}

This article was presented as a poster at the 2019 Annual Fall Conference of the Korean Association of Human Development.

\section{Conflict of Interest}

No potential conflict of interest relevant to this article was reported.

\section{References}

\section{In English}

Cha, S.-S., \& Seo, B.-K. (2018). Smartphone use and smartphone addiction in middle school students in Korea: Prevalence, social networking service, and game use. Health Psychology Open, 5(1), 1-15. doi:10.1177/2055102918755046

Cho, M.-H. (2004). The strength of motivation and physical activity level during leisure time among youth in South Korea. Youth \& Society, 35(4), 480-494. doi:10.1177/0044118X03258242

Coleman, J. S. (1990). Foundations of social theory. Cambridge, MA: The Belknap Press of Harvard University Press.

Dika, S. L., \& Singh, K. (2002). Applications of social capital in educational literature: A critical synthesis. Review of Educational Research, 72(1), 31-60. doi:10.3102/00346543072001031

Elhai, J. D., Dvorak, R. D., Levine, J. C., \& Hall, B. J. (2017). Problematic smartphone use: A conceptual overview and systematic review of relations with anxiety and depression psychopathology. Journal of Affective Disorders, 207, 251259. doi:10.1016/j.jad.2016.08.030

Kline, R. B. (2005). Principles and practice of structural equation modeling (2nd ed.). New York: Guilford Press.

Laible, D. (2007). Attachment with parents and peers in late adolescence: Links with emotional competence and social behavior. Personality and Individual Differences, 43(5), 1185-1197. doi:10.1016/j.paid.2007.03.010

Lapierre, M. A., Zhao, P., \& Custer, B. E. (2019). Short-term longitudinal relationships between smartphone use/ dependency and psychological well-being among late adolescents. Journal of Adolescent Health, 65(5), 607-612. doi:10.1016/j.jadohealth.2019.06.001

Otto, L. B., \& Atkinson, M. P. (1997). Parental involvement and adolescent development. Journal of Adolescent Research, 
12(1), 68-89. doi:10.1177/0743554897121005

Oulasvirta, A., Rattenbury, T., Ma, L., \& Raita, E. (2012). Habits make smartphone use more pervasive. Personal and Ubiquitous Computing, 16, 105-114. doi:10.1007/s00779011-0412-2

Poortinga, W. (2006). Social relations or social capital? Individual and community health effects of bonding social capital. Social Science \& Medicine, 63(1), 255-270. doi:10.1016/ j.socscimed.2005.11.039

Parcel, T. L., \& Dufur, M. J. (2001). Capital at home and at school: Effects on child social adjustment. Journal of Marriage and Family, 63(1), 32-47. doi:10.1111/j.17413737.2001.00032.x

Putnam, R. (1993). The prosperous community: Social capital and public life. The American Prospect, 13, 35-42.

Putnam, R. (1995). Bowling alone: America's declining social capital. Journal of Democracy, 6(1), 223-234. doi:10.1007/978-1349-62965-7_12

Rideout, V. J., Foehr, U. G., \& Roberts, D. F. (2010). Generation M2: Media in the lives of 8-to 18-year-olds. Kaiser Family Foundation. Retrieved from https://files.eric.ed.gov/fulltext/ ED527859.pdf

Steiger, J. H. (1990). Structural model evaluation and modification: An interval estimation approach. Multivariate Behavioral Research, 25(2), 173-180. doi:10.1207/s15327906mbr2502_4

UNICEF. (2011). The state of the world's children 2011: Adolescence-an age of opportunity. New York: United Nations Children's Fund(UNICEF).

West, S. G., Finch, J. F., \& Curran, P. J. (1995). Structural equation models with nonnormal variables: Problems and remedies. In R. H. Hoyle (Ed.), Structural equation modeling: Concepts, issues, and applications (pp. 56-75). Thousand Oaks, CA: Sage Publications.

Wu, Q., Xie, B., Chou, C. P., Palmer, P. H., Gallaher, P. E., \& Johnson, C. A. (2010). Understanding the effect of social capital on the depression of urban Chinese adolescents: An integrative framework. American Journal of Community Psychology, 45, 1-16. doi:10.1007/s10464-009-9284-2

\section{In Korean}

Bae, S.-M. (2014). The effects of perceived parenting style and peer relationship satisfaction on addictive use of cellular phone and depression for middle school students. Korean Journal of Youth Studies 21(11), 271-290.

Bae, S.-M. (2018). The influence of smartphone usage type on social capital. Korean Journal of Youth Studies, 25(10), 205223. doi:10.21509/KJYS.2018.10.25.10.205

Baek, S.-H., \& Chung, H.-W. (2015). Longitudinal mediated effects of depression on the relation between mobile phone dependence and learning activity. Korean Journal of Counseling, 16(5), 355-370. doi:10.15703/kjc.16.5.201510.355

Chang, S., Song, S., \& Cho, M. (2012). The effects of perceived positive parenting attitude on mobile phone dependency: The mediating roles of self esteem and attachment to peer. Korean Journal of Youth Studies, 19(5), 161-187.

Cho, Y. (2019). Trajectory of smartphone dependency and associated factors in school-aged children. Korean Journal of Child Studies, 40(6), 49-62. doi:10.5723/kjcs.2019.40.6.49

Ha, M. (2014). The latent classes depending on trajectories of mobile phone dependency and its relationship with psychological and emotional characteristics amongst adolescence. Asian Journal of Education, 15(4), 313-336. doi:10.15753/ aje.2014.15.4.013

Heo, G. (2015). A study on the time-dependent effects of parent attitude on the changing trajectory of adolescents' cell phone dependency. Korean Journal of Youth Studies, 22(3), $59-76$.

Hong, S. (2000). The criteria for selecting appropriate fit indices in structural equation modeling and their rationales. Korean Journal of Clinical Psychology, 19(1), 161-177.

Huh, M. Y. (2000). The study for the development and validation of 'parenting behavior inventory' perceived by adolescent (Doctoral dissertation). Retrieved from http://www.riss.kr/ link?id=T10397901

Hwang, G.-W., Cho, Y.-J., \& Hyun, M.-H. (2016). The mediating effect of school adjustment on the relationship between attachment to peer and mobile phone. Korean Journal of Youth Studies, 23(8), 219-239. doi:10.21509/KJYS.2016.08.23.8.219

Jin, M. R., \& Shin, S. (2016). The effects of attachment trauma, self-esteem, depression, self-regulation on smart phone addiction in Korean adolescents: Focusing on escape theory model. Korean Journal of Psychology: Addiction, 1(1), 31-53.

Jun, S. (2014). Longitudinal relationship between overuse/addictive use of mobile phones and depression in adolescents: Adapting the autoregressive cross-lagged model and multiple group analysis across gender. Family and Environment Research, 52(3), 301-312. doi:10.6115/fer.2014.026

Jun, S. (2015). The complex effects of the purposes of using mobile phones on mobile phone dependency and depressive symptoms among elementary school students. Journal of Digital Convergence, 13(10), 471-482. doi:10.14400/ JDC.2015.13.10.471

Kim, J.-H. (2012). The effects of parental factors, friend's factors and personal factors on the mobile phone dependency of youth mediated by mobile phone uses. Journal of Adolescent Welfare, 14(3), 97-120.

Kim, J. M., \& Song, S. J. (2015). The structural relationship among depression, mobile phone dependency and academic 
adjustment of adolescents. Korean Journal of Youth Studies, 22(6), 389-408.

Kim, K. I., Kim, J. H., \& Won, H. T. (1984). Ganijeongsinjindangeomsa silsi yogang [간이 정신진단검사 실시요강]. Seoul: Jungangjeokseongchulpansa.

Kim, K., Jo, E., \& Song, J. (2018). The effects of parental monitoring and intrusiveness on addictive use of cellular phones: A seven-wave latent growth model analysis. Studies on Korean Youth, 29(1), 7-32. doi:10.14816/ sky.2018.29.1.7

Kim, M. (2015). The subjective well-being of Korean children and its policy implications. Health and Welfare Policy Forum. Retrieved from December 19, 2020, from http://repository. kihasa.re.kr

Kim, S. (2016). The longitudinal relationship between use of smart phone and depression and aggression in adolescents using autoregressive across-lagged modeling. Secondary Education Research, 64(2), 315-336. doi:10.25152/ser.2016.64.2.315

Kim, S., \& Han, Y. (2015). The moderating effect of afterschool caregiver absence between school adjustment and mobile phone dependency in early adolescence. Korean Journal of Child Studies, 36(1), 147-162. doi:10.5723/ KJCS.2015.36.1.147

Kim, Y. (2019). Eoriniwa cheongsonyeonui hyudaepon boyu mit iyonghyeongtae bunseok [어린이와 청소년의 휴대폰 보유 및 이용형태 분석]. KISDI STAT Report. Retrieved from October 22, 2020, from http://www.kisdi.re.kr

Kim, Y.-S. (2019). Identifying the latent class and latent transition influence variables regarding the longitudinal development of adolescence mobile phone dependency. The Journal of Child Education, 28(3), 45-71. doi:10.17643/KJCE.2019.28.3.03

Lee, A.-R., \& Lee, K.-G. (2012). The effects of parental factors, friend's factors, and psychological factors on the addictive mobile phone use of children. The Korean Journal Child Education, 21(2), 27-39.

Lee, J.-S., \& Myung, S.-Y. (2007). A study of adolescents' peer relation and school life maladjustment according to their mobile phone use and addiction. Journal of Korean Home Management Association, 25(4), 67-86.

Lee, J. Y., \& Chung, I. J. (2018). Developmental trajectory of mobile phone dependency among youth and its psychological/emotional predictors. Journal of School Social Work, 42, 101-122. doi:10.20993/jSSW.42.5

Lee, S. H., Kim, H. S., Na, E. Y., Lee, S. Y., Kim, S. N., Bae, J. H.,...Yang. J. Y. (2002). A study on the effects of mobile phone use of adolescents (Report No. 2002-1). Seoul: Samsung Life Public Welfare Foundation.

Lee, W. K., Rhee, S.-H., Kim, M. J., \& Kim, S. (2020). Employed mothers' work-family conflict and early schoolage children's smartphone dependency: Depression and parenting behaviors as sequential mediators. Korean Journal of Child Studies, 41(2), 147-161. doi:10.5723/ kjcs.2020.41.2.147

Min, B.-S. (1991). The influence of school life adjustment and selfconcept on academic achievement (Unpublished master's thesis). Hongik University, Seoul, Korea.

Mo, S. H. (2018). Influence of depression on mobile phone dependence of adolescent: Moderator effect comparison of peer attachment and school relationship factor according to gender. Korean Journal of Youth Studies, 25(8), 55-80. doi:10.21509/KJYS.2018.08.25.8.55

Nam, H., \& Ha, E. (2019). The effects of aggression and depression on mobile phone dependency among children in community service centers. Journal of the Korean Society of Child Welfare, 65, 1-21. doi:10.24300/jkscw.2019.03.65.1

Seo, M. (2016). The influence of changes in mobile phone use by purposes on psychosocial maladjustment among early adolescents. Asian Journal of Education, 17(4), 239-261. doi:10.15753/aje.2016.12.17.4.239

Seo, J. A. (2013). The effects of social capital and social expenditures on the subjective well-being of adolescents-Evidence from 16 OECD countries (Doctoral dissertation). Retrieved from http://www.riss.kr/link?id=T13143247에서 인출

Sung, Y. S. (2008). Mobile phone dependency, motivations and effects of mobile phone usage among Korean adolescents. Korean Journal of Child Studies, 29(4), 181-197.

Woo, S. (2013). The effects of parental abuse and neglect, and children's peer attachment, on mobile phone dependency. Family and Environment Research, 51(6), 583-590. doi:10.6115/fer.2013.51.6.583

Yang, S.-Y., \& Park, Y.-S. (2005). A prediction model of cellular phone addiction tendency among adolescents. Family and Environment Research, 43(4), 1-16.

\section{ORCID}

Jieun Kim http://orcid.org/0000-0001-8617-5845

Saerom Park http://orcid.org/0000-0001-6863-5406

Hye Jun Park http://orcid.org/0000-0002-5950-7362

Received October 31, 2020

Revision received December 24, 2020

Accepted February 4, 2021 
